\title{
Availability and requirements in UK retail markets - New data sets
}

Received (in revised form): 15 May 2007

\section{Bob Thompson}

is the founder of RETRI Group, established in 2001 as a research consultancy in real estate. For the previous 16 years he was a partner at King Sturge. His clients range from Investors and Fund Managers to Developers and Local Authorities. Although most widely published as an expert in industrial property, he has been involved in the whole spectrum of property types, including some of the largest schemes in Europe. He is a past President of the European Real Estate Society, a visiting research fellow at Reading University and a senior research associate at the College of Estate Management.

\begin{abstract}
Unlike other mainstream sectors, UK retail has never benefitted from comprehensive data sets of supply and demand. Analysis of the market has always focused upon the top end of the market, reporting new developments, expenditure-based demand and prime rents. New data has, however, emerged from agency-based information systems that give a comprehensive view of these markets at a low level over the last decade. This paper examines this data through the use of three towns representing different levels of the retail hierarchy and reports upon its characteristics.
\end{abstract}

\section{Keywords:}

retail, requirements, take-up, average rents

Journal of Retail and Leisure Property (2007) 6, 195-201. doi:10.1057/palgrave.rlp.5100063

\section{INTRODUCTION}

For most property markets, the standard metrics are well known, even if the data are not. Availability represents current supply and take-up is the measure of market demand. The retail market in the UK has, however, never seen the development of the same variables over a reasonable time series.

There are a number of reasons for this. First, the retail sector was the first to see any serious research attempt to understand the relationships between underlying variables (eg Jones, ${ }^{1}$ Rams $^{2}$ and Potter ${ }^{3}$ )

Bob Thompson RETRI Group 44 Stewart Avenue Upminster RM14 2AF, UK Tel: +44 (o) 7703234251 E-mail: bt@retrigroup.com
Groundbreaking as this research was, inevitably it was constrained by a lack of market data.

Secondly, the market-driven paymasters of the research effort, by and large, concentrate at the prime end of retail that seldom sees any serious voids. As a consequence availability data, covering the whole market, was seen as unimportant. 
On the demand side, great emphasis was placed upon the strong linkages between retail expenditure and prime retail space leading to the development of analytical tools for modelling retail location. In parallel, firms such as Hillier Parker were developing indices of performance that monitored how rents and yields changed on a regular basis.

Retail requirements were regarded purely as an operational tool for pushing space rather than as having any analytical value.

Perfect Information Property has been providing an aggregation service to agents for the last 15 years. Retailer requirements are researched actively every month as are details of vacant space. The resulting UK wide database has provided a monthly picture of the retail property market since 1995 . These data only became available for analysis recently but give the ability to show supply and demand in the retail sector over a 10-12-year time series at the level of individual High Streets. This paper examines these data sets and draws out the relationships embodied within them.

Because of the way the data are constructed, it is not possible to identify whole market requirements, that is, at a national level. Similarly, it is not possible to disaggregate national sales data to a town level. Comparisons can, however, be made between local performance and national data.

Research into the similarities of High Streets ${ }^{4}$ for the New Economics Foundation examined towns across the UK, measuring the extent to which the retail offer had become standardised. This generated a classification of towns into 'Home Towns', where diversity had been retained; 'Clone Towns', where the High Street was dominated by chain retailers and were consequently less diverse; and 'Border Towns' where continued diversity was at threat. This research concentrates on examples of each of those categories:

\section{Guildford: Clone town}

While Guildford offers some of the best shopping in the South East, the main high streets consists almost exclusively of chain stores. Independent shops have been priced off the High Street by a rental premium of four to five times over secondary space. Guildford has the most expensive highstreet rents in the country, second only to central London.

The High Street area is dominated by chain stores that have over 70 per cent of the space. Over a quarter of all shops are clothing retailers and food retail represents less than 2 per cent of high-street outlets, and is all controlled by chain stores.

\section{Ashford: Border town}

Ashford is a market town that has outgrown itself. The number of chain stores on the high street is just above 50 per cent and diversity on the high street is already very low.

While there are a reasonable number of restaurants, clothes stores and professional-services firms, there are few or no food retailers or leisure shops. 
Table I: Overall retail stock

\begin{tabular}{ll}
\hline & Sq ft (millions) \\
\hline Guildford & 3.1 \\
Ashford & 2.5 \\
Lewes & 1.6 \\
\hline
\end{tabular}

\section{Lewes: Home town}

Despite its location between London and Brighton, Lewes in East Sussex has so far managed to keep much of its traditional character and sense of individuality. A survey of the busiest part of the high street showed that locally owned independent stores were in the majority in most categories of outlet, only ousted by pharmacy and healthcare stores and department and catalogue stores.

In total, local independent shops represented over 70 per cent of the outlets in the high street. Even in categories where local shops often find it hard to compete, such as retail clothing, local shop owners represented over 60 per cent of the outlets.

These centres represent different levels of the retail hierarchy and have significantly different levels of retail stock as shown in Table 1.

\section{REQUIREMENTS}

Anyone familiar with requirements data will know how problematic this can be. Data can be multiply duplicated as agents circulate details in the market; they can be vague, where retailers themselves do not specify narrow enough markets; and they can be ephemeral, coming and going very quickly.

The sources of this data are retailers themselves who, having determined their expansion plans, publish lists of target towns. These locations are seldom set in stone and many retailers hedge their bets by giving numbers of stores and broad geographic areas only.

Secondly, these requirements are taken up and published further by information services such as Focus and Propertymall and by instructed agencies. The PIP system has three important differences:

- requirements are researched actively from all retailers, not just the high-street giants;

- the data is monitored and filtered to weed out duplicates; and

- individual towns are populated from regional lists, thus giving an accurate record of putative demand for space at the town level.

Figure 1 shows the requirements return for the three towns, quarter by quarter between 1995 and the end of 2006. Clearly there is a high degree of correlation between the locations, particularly between Guildford and Ashford where the correlation coefficient is 0.91 . Lewes is less closely correlated at 0.48 with Ashford and 0.57 with Guildford. 


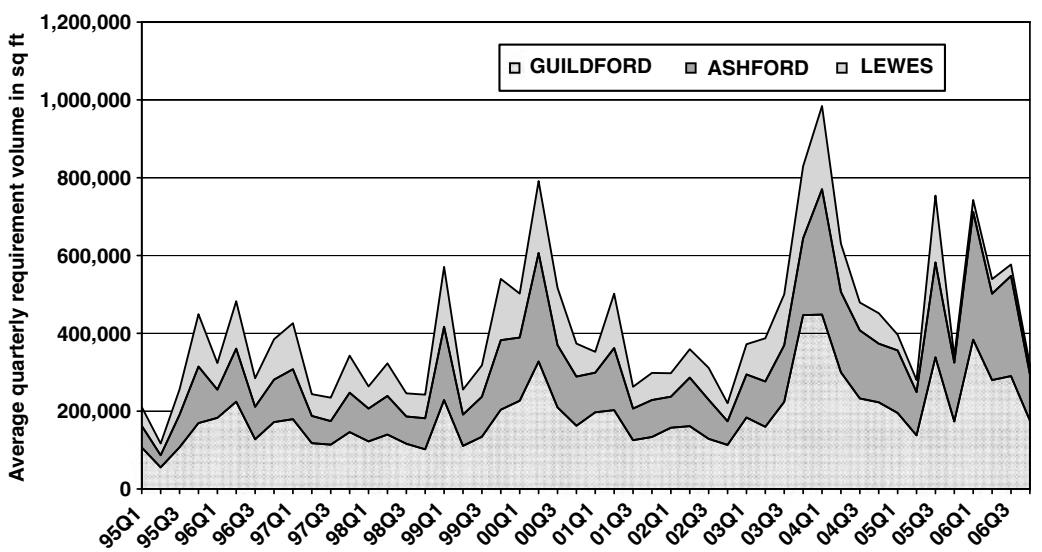

Figure 1: Requirements in three towns 1995-2005

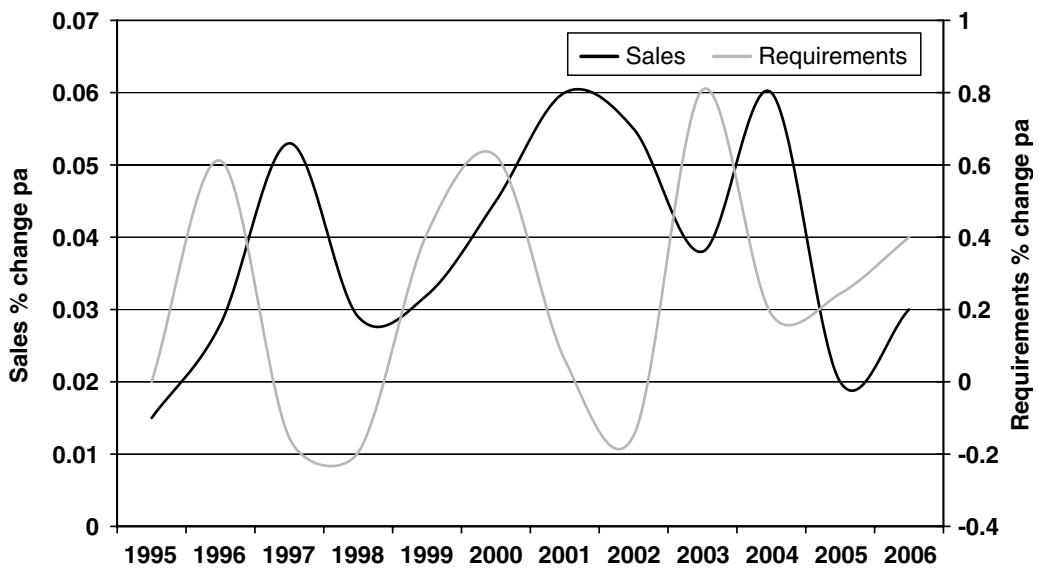

Figure 2: Retail sales vs requirements

In part this close correlation may reflect their physical proximity all are located in the South East; however, tests with centres in other regions show similarly high degrees of correlation.

The key question is whether or not the PIP requirements data reflect changes in demand for retail space accurately.

The key demand side driver for retail profitability is the value of retail sales, since this records the money actually being spent in shops. Logically profitability should itself impact upon affordability and the wherewithal to grow by seeking additional selling space.

Figure 2 shows changes in the relationship between retail sales and requirements in Guildford using annualised data. Notwithstanding the significant difference in volatility apparent in the data, changes in sales volume appear to lag changes in requirements volume by about a year. The correlation coefficient here is 0.72 . The lagged relationships with national sales are significantly less strong for Ashford (0.54) and Lewes (0.32). 
Do these relationships pass a reality check? After all, common sense would dictate that added profitability should drive expansion rather any expectation of future profits. This is, however, requirements data - a manifestation of retail hopes and plans. Already it has been noted that requirements can melt away in the face of a turn down in demand. Retailers may not be prescient, only watchful.

With respect to the type of towns, this too seems reasonable. Guildford should be the most like the national picture and Lewes the least.

\section{AVAILABILITY}

A decent supply side series has been almost universally absent from the retail sector for the reasons described previously. The market focus upon prime property has been reinforced by the use of retail development starts from construction statistics as a proxy for supply.

Figure 3 shows total availability month by month between 1995 and 2006. The slowdowns in the late 1990s, 2002-2003 and 2005 appear as lagged increases in the amount of space available as would be expected.

The data for the three towns follow a similar pattern save that availability is far lower in Lewes than in either Guildford or Ashford and that the current slowdown is having a relatively muted effect upon availability in these towns (Figure 4).

\section{RENTS}

The acid test for these data sets is whether or not the embedded relationships have any bearing on retail rents in the chosen locations. Popularly, rents are quoted as 'Prime Zone A' and, oddly enough, never seem to go down whatever the economic circumstances. These are unlikely to correlate with the data in any meaningful way.

Instead an average rental series has been calculated using details of actual transactions completed and rents paid in each location. These give a much more sensitive indicator of activity in the market.

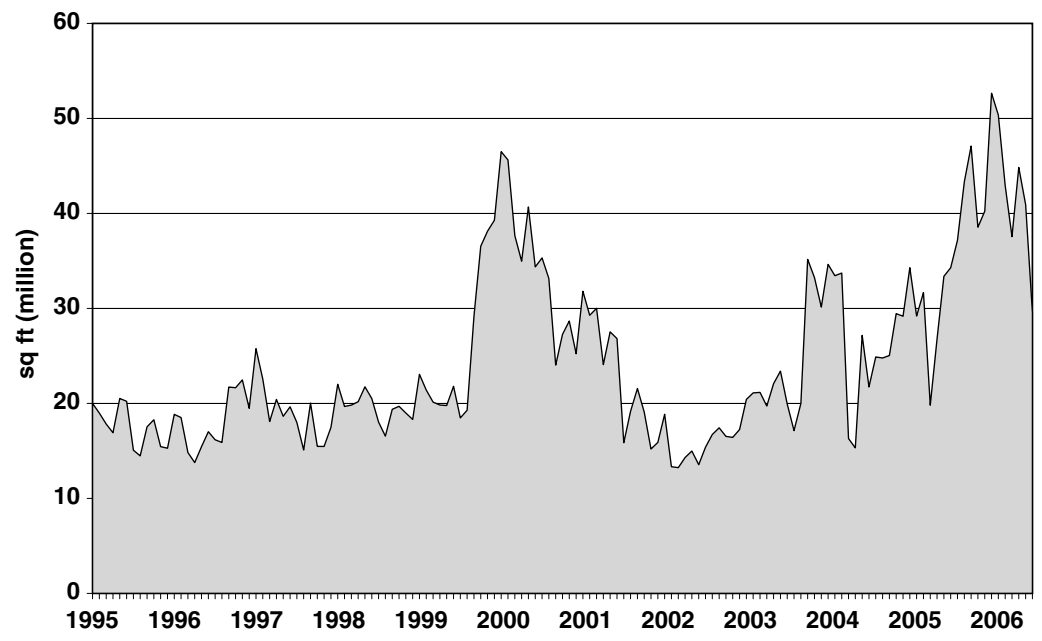

Figure 3: UK retail availability 


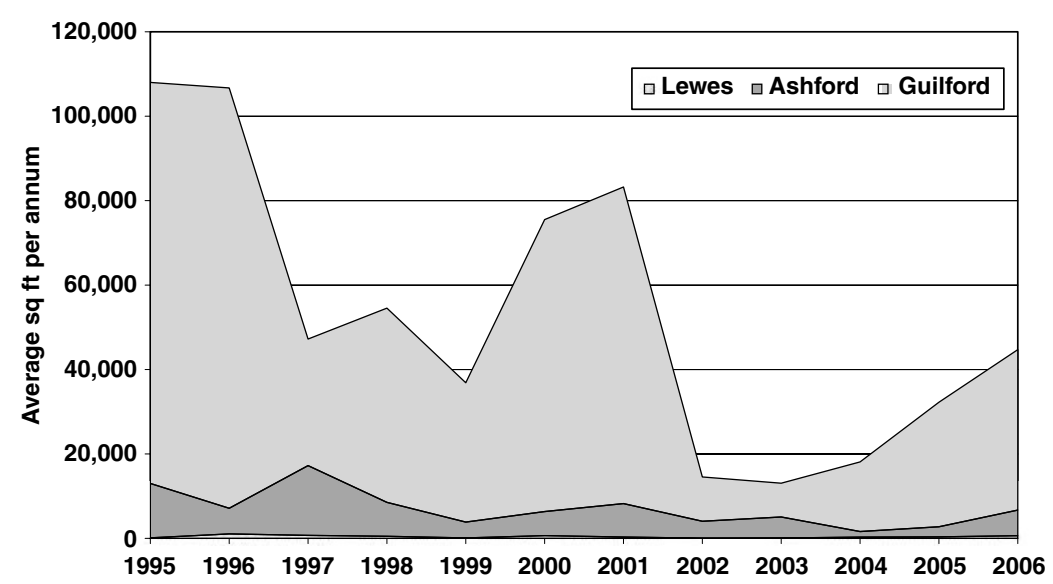

Figure 4: Availability in study towns

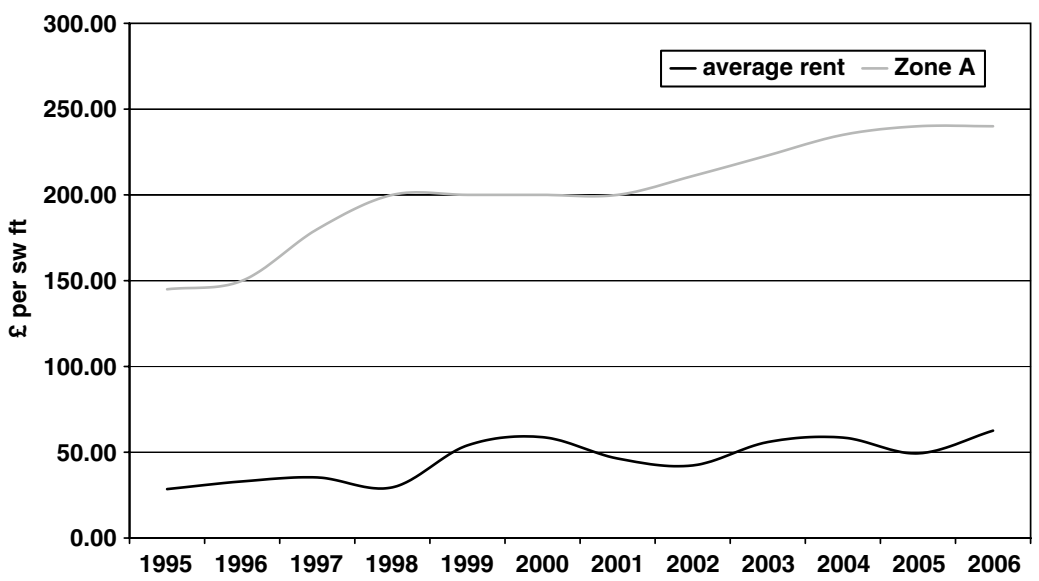

Figure 5: Guildford retail rents

Figure 5 shows the comparison between Guildford Zone A and average rents paid.

Using linear regression to test the relationships between requirements (as a proxy for demand), availability (as a proxy for supply) and average rent produced mixed results. Analysis of Guildford produced a surprisingly high correlation factor of 0.83 indicating that a very significant proportion of the movement in average rents is explained by movements in requirements and availability. Ashford saw a much more comfortable result with a return of 0.56 and Lewes saw a positive correlation of 0.35 .

\section{CONCLUSIONS}

It is axiomatic that the more High Streets become the same, the more predictable they will become. These data sets seem well correlated with the 'Clone Town' High Streets as represented by Guildford and give a 
comprehensive picture of the monthly market activity over the past decade or so.

For the 'Home Towns' as represented by Lewes, the situation is less clear. Relationships within the data sets are less well established and correlations much lower with external variables. In part, this may well just describe how different these towns are and undoubtedly reflects a lack of volume in the market.

The 'Border Towns', with Ashford as an example here, actually saw relatively strong relationships and correlations between the data sets themselves and with external variables.

The objective of this paper was to examine these data sets of requirements and availability and test them as a resource for UK retail analysis. On the basis of this analysis they will perform a useful function in support of analysis of the larger centres; however, the smaller and more diverse the market becomes, the more variable becomes the data.

Further data sets are available that disaggregate local data by type of market (High Street, Shopping Centre and Out of Town), for example and by retailer type opening up the prospect of further, more granular research.

\section{References}

1. Jones, P. (1978). Small Shops and Local Shopping: Bibliography \& Research, URPI, Reading.

2. Rams, E.M. (1976). Analysis and Valuation of Retail Locations, Reston Publishing, Reston.

3. Potter, R. (1982). The Urban Retailing System, Blackwell, London.

4. Conisbee, M., Kjell, P., Oram, J., Bridges-Palmer, J., Simms, A. \& Taylor, J. (2005). Clone Town Britain, New Economics Foundation, London. 